\title{
The Influence of Social Media on Collective Action in the Context of Digital Activism: An Affordance Approach
}

\author{
Manju K. Ahuja \\ University of Louisville \\ manju.ahuja@louisville.edu
}

\author{
Pankaj Patel \\ Villanova University \\ pankaj.patel@villanova.edu
}

\author{
Ayoung Suh \\ City University of Hong Kong \\ ahysuh@cityu.edu.hk
}

\begin{abstract}
This study examines how social media influence collective action in the context of digital activism. This is achieved by using the concept of media affordance as a theoretical lens and applying it to the collective purposes of network building and synthesis, as suggested by mobilization theory. Employing latent class logit regression, we tested the proposed hypotheses based on data from 384 digital activism events in 100 countries, classifying success in digital activism as either partial or complete success. The results show that when the purpose of digital activism is network building, media with greater affordances for promoting environmental shaping were positively related to the success of digital activism. Conversely, when the purpose of digital activism is synthesis, media with greater affordances for promoting contagion were positively related to the success of digital activism.
\end{abstract}

\section{Introduction}

Events in recent years have shown that new media technologies have not only increased the civic engagement of citizens around the world, but have also facilitated greater activism. For example, Moveon.org mobilized more than three million members in a campaign against the Iraq War using online media [55]; social media played a major role in events ranging from social injustice based movements in Madrid (Indignados), New York (Occupy Wall Street), and Athens (protests against austerity measures) to overthrowing an autocratic regime in Egypt [6, 9].

Evidence shows that more people are increasingly engaging in political or civic engagement using diverse social networking sites, and social media is acting as an important catalyst for social movements [32]. The use of modern communication technologies to initiate and manage social and civic movements is referred to as digital activism [27].
Due to the perceived importance of social media as a pivotal tool for civic, environmental, social, and economic activism, scholarly attention has focused on the increasingly significant role played by social media in collective action [10, 40]. Although the political, cultural, and societal contexts of different countries are known to affect digital activism's outcomes, recent empirical evidence has shown that the use of social media has a certain influence on collective action [42]. Accordingly, one of the key decisions in digital activism efforts requires understanding how best to harness social media in order to seek, build, and sustain digital resources to meet digital activism's specific goals [6]. However, little is known about how the functions and dynamics of social media differ according to the purposes of digital activism $[49,51]$.

To fill this gap in understanding, we examine the roles of social media in promoting collective action in the context of digital activism. Towards that end, following the current scholarship focusing on the concept of media affordances, we explore the influence of different social media on collective action from the affordance lens in the context of digital activism.

The study makes two key contributions. First, it contributes to developing the theory of media affordances by proposing new media affordances associated with the dynamics of a collective - in this case, a mass of anonymous people. Researchers have mostly examined media affordances at the micro level using explorative approaches in the context of organized groups, which are often described as "social aggregates that involve mutual awareness and potential mutual interaction" [38]. The findings of this study, as applied to the social media setting, can help researchers understand the new media affordances and their effects on collective action. Second, this study contributes to the information systems (IS) literature on media choice by linking the notion of social homogeneity to the affordances of social media. Understanding how social media induce social homogeneity from a collective can aid in the design of a social media strategy to enhance the performance of a collective in accomplishing its goals. Thus far, the IS literature has focused on the 
homogenous behavior of individuals (e.g., herd behavior in technology adoption or shopping behavior), concentrating mainly on psychological, social, and normative factors $[51,52]$. By developing a more nuanced understanding of how technology induces homogeneity among a collective to achieve a specific aim, this study paves the way to broadening our understanding of the role of social media in promoting collective action towards a particular purpose in the digital environment.

\section{Theoretical Development}

Digital activism is based on homogeneous activities performed by a large number of people in pursuit of the shared collective purpose. It can be conceptualized as collective behavior that aims at network building and the synthesis of ideas [47, 48].

From the point of view of a collective, as opposed to a single individual, researchers have argued that individuals are motivated and behave similarly toward common attitudes and practices in activism [3, 4, 43]. Kane et al. [29] have proposed two mechanisms that underlie social homogeneity in social media platforms: environmental shaping and contagion. Environmental shaping refers to how the structural features of a social media platform encourage users to connect with others and come together quickly, thereby creating and expanding a digital environment. Contagion refers to how the content features of a social media platform enable users to share, process, and spread similar information so that participants can disseminate attitudes, norms, and practices through interaction [29].

We employ the mechanisms of environmental shaping and contagion to explain how social media platforms provide different affordances that allow collectives to achieve different purposes in digital activism. We assume that digital activism requires the homogeneous behavior of individuals to achieve a collective purpose, with the participants in the collective encouraged to influence and inform each other and to share the same content in a digital environment to enable them to quickly build a large network. We suggest that environmental shaping and contagion underpin the two main goals of digital activism: network building and synthesis.

Mobilization theory postulates that the two primary purposes of digital activism are: (a) identifying people with relevant, potential interests in digital activism's purpose and allowing those participants to maintain communication (network building); and/or coordinating, integrating, or synchronizing participants' contributions (synthesis) [47, 48].

Network building in digital activism requires participation and mobilization [28]. Ultimately, it involves connecting different actors, issues, and events to initiate collective action [19]. To develop and mobilize a network of connected individuals who instrumentally identify with a particular activism, information must be rapidly transmitted across different actors, organizations, and time and space [2, 28, 34, 49].

Synthesis in digital activism aims to combine information from multiple sources and to understand and modify the mental models of a situation [31]. Thus, it requires participants to carefully craft the message to ensure that the intended meaning is expressed clearly, that aggregate multiple sources of information are included to ensure that the alternative visions of activism are debated, and that collective action is organized around shared views [2, 30].

\subsection{Affordance Approach}

The concept of affordance, as defined by Gibson [21], has been adopted in the IS literature to explain how the mutuality of users' intentions and technology capabilities provide the potential for a particular action $[33,37]$. The affordance lens provides researchers with the theoretical grounds to explain the symbiotic relationships between people and technology [37] that can shed light on the dynamics of digitally mediated social change.

Researchers argue that the affordances of social media may cause dialectic tension that can both enable and constrain a particular action [33]. In essence, the same media affordance may lead to different results depending on the conditions in which the social media are used. The results can be used to explain how social media platforms function positively or negatively to achieve the particular goals of digital activism.

\subsection{Social Media Affordances for Collective Action}

Network building and synthesis require different collective activities. Activities essential for network building involve creating and expanding a digital network in which participants can identify relevant and potential interests and maintain communication with others so that they can feel a sense of participation [20]. Activities vital for synthesis are aggregating diverse pieces of information from multiple sources to 
create a coherent message by facilitating in-depth sharing of more reliable information with trusted counterparts [6]. By mapping the main mechanisms for social homogeneity [20] and the purposes of digital activism $[15,16]$, we contend that that the social media affordances - connecting ties and visualizing network information - enhance a collective's ability to build a large network because these affordances promote environmental shaping in a social media platform. We also contend that two other social media affordancesdeep profiling and controlling privacy-enhance the ability of a collective to share information and reach a consensus for decision-making because these affordances promote contagion.

\subsection{Network Building}

In digital activism, the foundation of network building is connecting individuals through the sharing of common interpretations of events via a digital platform [4, 50], which is akin to social capital building [44]. While Putnam et al. [45] have shown that social capital enhances political participation offline, the features of political participation online remain unexplored. Environmental shaping is key to creating a loosely coupled network connecting diverse users widely dispersed across a variety of feeds and networks [35, 49]. Research suggests that (a) designing ties and (b) visualizing network information are affordances associated with environmental shaping [29].

The affordance of connecting ties consists of two social media features: the connection mode and the type of tie. The mode of the connection refers to the methods used to establish and connect ties. Some social media platforms (e.g., Facebook) allow a tie to exist only when both parties in the relationship confirm the tie (symmetric tie connection). In contrast, some media (e.g., Twitter) allow an asymmetric tie connection in which a tie can exist without both parties confirming the relationship. In digital activism, the mode of an asymmetric tie connection is more effective for network building because people are more likely to be connected with other actors in a timely manner when the media platform does not require both parties in a relationship to approve the tie. Some researchers have argued that media users feel more comfortable connecting with potential supporters that do not directly belong to their personal networks when they share a common civic or social goal than they do connecting with those with whom they are acquainted $[35,49]$. The features of an asymmetric tie connection afford a cross-cutting transmission belt connecting diverse users located in different temporal, spatial, and ideological areas of the activism sphere.

The type of tie refers to the content flow in a tie. The tie types of interest here are emotional and instrumental in nature [53]. Emotional ties are characterized by the exchange of socio-emotional information, and they represent relational states between individuals, such as friends on Facebook. In contrast, instrumental ties are characterized by the information flow between two nodes. Instrumental ties support environmental shaping better than emotional ties because the flow of information facilitates a rapid expansion of weak-tie networks in which people do not share their communications with a defined audience but are unrestricted by spatial or relational boundaries [6]. Thus, they can immediately develop a flow of information, described as a 'cascade.' The functions of social media that support information flow (e.g., RSS, Twitter trends, retweets, and bookmarking systems) and facilitate public engagement foster increased information flows between network participants [22].

The second affordance of social media associated with environmental shaping is visualizing network information, which makes it possible for users to see and traverse network connections, thus enabling them to identify how they are connected with others and understand their own network information (e.g., the number of ties, position in a network, or strength of the ties). The affordance of visualizing network information also gives people easy access to the network information of others so they can understand how people are connected to content and how content is connected to other content [29]. Therefore, the affordance of visualizing network information can assist those who wish to leverage network information strategically to expand or build a network to increase resource accessibility [7]. However, this is not the case with digital activism. The availability of network information allows users to view the activities, social identities, political views, interests, and preferences of others in the network [4]. As reported previously, people tend to be reluctant to allow third parties to access their network information [11]. Thus some individuals may choose not to participate in the activism network and its related activities. Indeed, in a case study of the Occupy Wall Street movement, Penney and Dadas [42] revealed that many people felt their involvement in network building to support the activism would make them vulnerable to unwanted surveillance from authorities. Accordingly, the affordance of visualizing network information may not 
promote environmental shaping in the context of digital activism.

In sum, the degrees of affordances of connecting ties and visualizing network information vary across different social media platforms. The embedded technical features and the affordances can both enable and constrain the collective action to build a large network for digital activism. An increased affordance promoting environmental shaping (e.g., connecting ties) can expand the boundaries of a network beyond the participants' existing relational ties. In contrast, a decreased affordance for environmental shaping (visualizing network information) may constrain participation in an activist network because of fears related to sharing private network information and possible outside censorship [17]. Based on the discussion above, we propose the following hypotheses.

Hypothesis 1: When the aim of digital activism is to build networks, media with greater affordances for environmental shaping will increase the degree of success.

\subsection{Synthesis}

By allowing people to form online public spaces for extensive information sharing and deliberation, synthesis aims to aggregate diverse perspectives while coordinating and creating shared values to support social change [2]. The synthesis purpose of digital activism aligns with Dervin's individual sensemaking [14] where individuals aim to close cognitive gaps by focusing on a variety of information. Contagion is a key mechanism for synthesis; it leads people to interact with similar information and to enter into a dialogue, discussing issues of common interest and reaching a consensus for political decision-making [31]. We assume that the content features of social media shape how a collective establishes a shared mental model by influencing the transmission, exchange, and processing of content resources in a media platform [13, 46]. Thus, we suggest that contagion is associated with two social media affordances: (a) deep profiling and (b) controlling privacy.

Deep profiling is an affordance of social media that enables users to trace others' identities, contributions, and past activities [36]. The affordance of deep profiling supports contagion because it allows people to access information about their counterparts, including their political views, interests, and prior activities, thus leading to increased familiarity while helping to build a shared mental model among network participants $[8,31]$. In addition, deep profiling means people can identify what content was read (e.g., number of times "viewed") or how many people liked the content (e.g., "liked" on Facebook). Accordingly, the affordance of deep profiling increases the likelihood of users behaving similarly or following others based on what they have learned from the information others have shared [41]. It also determines how content flows across the network. For example, people have a tendency to read content simply because others have already viewed that content.

Controlling privacy is an affordance of social media that enables users to allow or restrict access to network resources [23]. Social media platforms offer people different degrees of privacy control [29]. For example, Facebook users are required to create a personal account before they can make relational ties with "friends" and access the content of their network of friends. In addition, users protect their privacy by inviting their friends to join their networks or by signing up for events and groups in which all the participants feel that they are able to control the outflow of private and valued information to other parties. If users do not want existing "friends" to access their content, they can control this access by breaking existing ties. Greater capabilities to protect access and privacy encourage people to contribute more personal content and in-depth information because they know their contributions will be shared only with those they trust [29, 52]. Therefore, the affordance of controlling privacy allows people without common experiences or shared mental models to better consider the context and interpret/integrate information from diverse sources, thereby achieving greater synthesis. Conversely, media with lower affordances for contagion could be less useful for this synthesis purpose. Based on the discussion, we can infer the following hypotheses:

Hypothesis 2: When the aim of digital activism is synthesis, media with greater affordances for contagion will increase the degree of success,

\section{Methods}

\subsection{Data Description}

The data for this study are from The Global Digital Activism Data Set version 2.0 (GDADS 2) [26]. The data represents 426 digital activism cases spanning 100 countries and dependent territories (e.g., HongKong or Macau). Compared to GDADS 1.0, GDADS 2.0 provides several advantages. The inter-rater reliability 
among the coders in classifying the outcomes was 0.691. Second, focusing on digital activism during 2010, 2011, and 2012 is important to avoid significant heterogeneity in evolution and diffusion of digital technologies. Access to digital technologies has increased significantly in recent years across most countries [5]. Thus, the narrow period of 2010, 2011, and 2012 attenuates significant unobserved heterogeneity related to country specific accessibility and diffusion rates of access to digital tools.

Among the 427 cases in GDADS 2.0, the level of success could not be determined for 42 cases. We dropped these cases to estimate the latent class logit model. The final sample consisted of 384 events from 100 countries from 2010 to 2012. The Appendix provides additional details on the country-distribution distribution of cases, the outcomes (partial success or total success) and the type of media tools used. As complete failure cannot be ascertained, partial success is coded as ' 1 ' and total success as '2.'

As country and period effects could still affect the efficacy of digital activism outcomes, we control for country dummies and include the year of digital activism.

The operationalization of variables is listed in Table 1. In line with the underpinnings of the latent class regression approach we include all the digital activism tools - website, forum, e-petitions, social networks, microblogs, digital video, digital maps, SMS, and whether digital activities were also conducted in the field. We control for whether violence or hacking was involved. We also control for the target type (government agency, business, or civil society group).

Table 1. Variable Description

\begin{tabular}{|l|l|}
\hline \multicolumn{1}{|c|}{ Variable } & \multicolumn{1}{c|}{ Description } \\
\hline Outcome & $\begin{array}{l}\text { Presence of website in the digital activism } \\
\text { efforts }\end{array}$ \\
\hline Site & Forums used in digital activism efforts \\
\hline Forum & $\begin{array}{l}\text { E-Petitions were used in the digital } \\
\text { activism efforts }\end{array}$ \\
\hline E-Petition & $\begin{array}{l}\text { Social Networks were used in the digital } \\
\text { activism efforts (e.g. Facebook) }\end{array}$ \\
\hline $\begin{array}{l}\text { Social } \\
\text { Networking }\end{array}$ & $\begin{array}{l}\text { Microblogs were used in the digital } \\
\text { activism efforts (e.g. Twitter) }\end{array}$ \\
\hline Microblogging & $\begin{array}{l}\text { Blogs were used in the digital activism } \\
\text { efforts }\end{array}$ \\
\hline Blog & $\begin{array}{l}\text { Videos were used in the digital activism } \\
\text { efforts }\end{array}$ \\
\hline Video & $\begin{array}{l}\text { Digital Maps were used in the digital } \\
\text { activism efforts }\end{array}$ \\
\hline Mapping &
\end{tabular}

\begin{tabular}{|l|l|}
\hline SMS & $\begin{array}{l}\text { SMS were used in the digital activism } \\
\text { efforts }\end{array}$ \\
\hline $\begin{array}{l}\text { Included } \\
\text { offline } \\
\text { participation }\end{array}$ & $\begin{array}{l}\text { Offline tactics were used in the digital } \\
\text { activism efforts }\end{array}$ \\
\hline Target Type & $\begin{array}{l}\text { Whether the target is a government } \\
\text { agency, business, or civil society group }\end{array}$ \\
\hline $\begin{array}{l}\text { Target } \\
\text { Country }\end{array}$ & Country where activism was started \\
\hline Year & Year activism started \\
\hline Violence & $\begin{array}{l}\text { Whether physical violence was initiated } \\
\text { by participants }\end{array}$ \\
\hline Hacking & $\begin{array}{l}\text { Whether hacking was initiated by } \\
\text { participants }\end{array}$ \\
\hline
\end{tabular}

\subsection{Analytical Approach}

As our earlier theoretical arguments are based on a configurations approach, and in light of increased calls for assessing complex configurations that may result from nine media types and use of offsite activities [12, $15,16,18]$, we use latent class logit regression.

First, using latent class approaches allow us to not begin with any a priori expectations regarding the number of segments of media and outcomes. Instead it allows for determination of a pertinent typology based on the structure in the data and the statistical fit of our models. Overall, using latent class logit regression we aim to assess configurations of media and the degree of success of digital outcomes (using a logit link function).

Although a complete exposition of latent class approaches are beyond the scope of this study, latent class models are based on mixture models. To identify most efficacious media-purpose profiles we used mixture models to estimate the likelihood of whether a specific digital activism into a class of media and degree of success configuration [54]. Mixture models facilitate the decomposition of a sample (indexed by $k$ ) for which a set of $n$ observations of digital activism $y_{\mathrm{m}}=\left(y_{\mathrm{mk}}\right)$ are available, in which there is a mixture of $\mathrm{S}$ media-purpose segments in proportions $\pi_{1, \ldots \ldots} \pi_{S}$. A priori, no information is available regarding from which segment (subgroup) in which a digital activism falls into. Although the likelihood of a digital activism falling into segments is constrained to 1 ,

$$
\sum_{s=1}^{S} \pi_{s}=1
$$

Given that the observations $y_{\mathrm{mk}}$ come from segment $\mathrm{s}$, the conditional distribution function of $y_{n}$ can be represented as $f_{s}\left(y_{n} \mid \theta s\right)$, where $\theta s$ is the 
vector of unknown parameters associated with the specific density function chosen, e.g., normal, Poisson, multinomial, Dirichlet, exponential gamma or inverse Gaussian. Mixture models are estimated using maximum likelihood, where the vector $\varphi=(\pi, \theta)$ is estimated based on the likelihood of $\phi$ being $L(\phi: y)=\prod_{n=1}^{N} f\left(y_{n} \mid \phi\right)$ where $f\left(y_{n} \mid \phi\right)=\sum_{s=1}^{S} \pi_{s} f\left(y_{n} \mid \phi_{s}\right)$

represents the unconditional probability of $y_{n}$, given $\phi$. Once an estimate of $\phi$ is obtained, using Bayes' theorem to calculate the posterior probability that any firm $n$ with $y_{m}$ comes from any segment $s$,

$$
p_{n s}=\pi_{s} f\left(y_{n} \mid \theta_{s}\right) / \sum_{s=1}^{s} \pi_{s} f\left(y_{n} \mid \theta_{s}\right) \text {. }
$$

\subsection{Model Selection}

As first step, we identify the number of classes that provide best fit for the underlying data. The number of different types of firm subgroups cannot be known $a$ priori. Numerous model selection heuristics have been proposed to determine segments for models. We use Log-likelihood (LL) to compare model fit across multiple segments, and use Bayesian Information Criteria (BIC) and Akaike Information Criteria (AIC) and Consistent CAIC. Segment solution with lowest values of LL, AIC, BIC, and CAIC fits the data best [1, 6].

As presented in Table 2, for the aggregate solution (i.e. or that there are no unique configurations of media and purpose that predict successful outcome of digital activism) ignores heterogeneity, and the possibility that different media-purpose outcomes could be more effective in realizing digital outcomes. Having found little support for the aggregate solution, we assessed the degree that different media-purpose profiles led firm subgroups to different performance outcomes.

Table 2. Model Selection

\begin{tabular}{|c|l|l|l|l|l|l|}
\hline Class & Par & LL & $\begin{array}{l}\text { MC } \\
(\mathrm{p})\end{array}$ & BIC & AIC & Entropy R $^{2}$ \\
\hline 1 & 26 & -115.4 & & 368.4 & 282.9 & \\
\hline 2 & $\mathbf{1 2 7}$ & $\mathbf{- 1 6 0 . 0}$ & $\begin{array}{l}1 \text { vs. } 2 \\
\text { P }<0.00\end{array}$ & $\mathbf{1 0 7 6 . 2}$ & $\mathbf{5 7 4 . 1}$ & $\mathbf{0 . 8 8 2 9}$ \\
\hline 3 & 243 & -119.5 & $\begin{array}{l}2 \text { vs. 3 } \\
\text { p }>0.1\end{array}$ & 1685.6 & 725.0 & 0.8584 \\
\hline 4 & 359 & -92.7 & $\begin{array}{l}2 \text { vs. 4 } \\
\text { p }>0.1\end{array}$ & 2232.7 & 903.5 & 0.8407 \\
\hline
\end{tabular}

Par: parameter, MC: Model Comparison
The two segment solution has the lowest values, and the highest Entropy R-square values, thus indicating the best fit with the data. The 3-, 4-, and 5segment solutions have increasing fit values, thus, indicating poorer fit for more than two segment solutions. We proceed with the two-segment solution.

\section{Results and Analysis}

The results from latent class logit regression are presented in Table 3. The two-segment solution led to classification of 196 digital activism in Class 1 and 189 digital activism efforts in Class 2. The interpretation of estimates is similar to a typical logit regression, only that estimates differ between identified groups. In Class 1, when the main purpose of digital activism is network building web sites $(\beta=6.9958, p<0.05)$ and blogs $(\beta=15.8535, p<0.05)$ improve the degree of success, whereas social networks $(\beta=-5.9031, p<$ $0.05)$, video $(\beta=-5.8171, p<0.05)$, and offline participation $(\beta=-9.5293, p<0.05)$ lowered the degree of success. In Class 2 , where the purpose of digital activism is synthesis social networks $(\beta=$ $12.3250, p<0.05)$, video $(\beta=7.7761, p<0.05)$, digital maps $(\beta=11.1016, p<0.05)$, and offline participation $(\beta=15.7829, p<0.05)$ increased degree of success, whereas blogs $(\beta=-23.9344, p<0.05)$ lowered the degree of success.

Table 3. Latent Class Logit Regression Model

\begin{tabular}{|c|c|c|c|c|}
\hline \multicolumn{5}{|c|}{ Model for Dependent } \\
\hline & \multicolumn{2}{|c|}{ Class 1} & \multicolumn{2}{|c|}{ Class 2} \\
\hline $\mathrm{R}^{2}$ & \multicolumn{2}{|c|}{0.856} & \multicolumn{2}{|c|}{0.9482} \\
\hline Updated_Output2 & Class1 & $z$-value & Class2 & $z$-value \\
\hline Intercept & & & & \\
\hline 1 & -2.655 & $\overline{2} .0464$ & 6.361 & 2.1366 \\
\hline 2 & 2.655 & 2.0464 & -6.361 & -2.1366 \\
\hline Predictors & Class1 & z-value & Class2 & $z$-value \\
\hline Web Site & 6.9958 & 2.4123 & 0.1592 & 0.0772 \\
\hline Forum & -1.489 & $\overline{0} .3266$ & 4.5843 & 0.2687 \\
\hline E-Petition & -0.0557 & $\overline{-}-0356$ & -0.2134 & -0.1163 \\
\hline $\begin{array}{l}\text { Social } \\
\text { Networking }\end{array}$ & -5.9031 & $\overline{1.7901}$ & 12.325 & 2.4276 \\
\hline Microblogging & 3.2442 & 1.256 & -2.297 & -1.3997 \\
\hline Blog & 15.8535 & 2.2946 & -23.9344 & -2.5997 \\
\hline Video & -5.8172 & $\overline{2.0869}$ & 7.7761 & 2.248 \\
\hline Digital Map & -5.9404 & $\begin{array}{l}- \\
1.5942\end{array}$ & 11.1016 & 1.8261 \\
\hline SMS & 0.0922 & 0.0166 & 18.1657 & 0.8807 \\
\hline $\begin{array}{l}\text { Offline } \\
\text { Participation }\end{array}$ & -9.5293 & $\overline{1.8447}$ & 15.7829 & 2.3245 \\
\hline
\end{tabular}




\section{Discussion}

The purpose of this study was to understand how social media platforms enable or constrain collective action in a digital environment. Drawing on the concept of media affordances against a backdrop of social homogeneity in the context of digital activism, we examined how the affordances of social media exerted a predictable influence on collective behavior in promoting environmental shaping and contagion. From this, we inferred the contingency of social media and the success of digital activism.

Based on our findings, we suggest that identifying the alignment of media affordances and the mechanisms for enabling or constraining collective action is essential to predicting the success of digital activism. We believe that these results will help guide digital activists' efforts to utilize media strategically to improve their chances of success. Using media with lower affordances to promote social homogeneity and realize a collective purpose could lead to ineffective digital campaigns. Furthermore, they could create coordination and communication problems, reduce the credibility of the cause, and, ultimately, lower the degree of digital activism success. Below, we discuss our results in detail and present the specific findings relating the purposes of digital activism and the capabilities of social media with to the mechanisms of social homogeneity.

\subsection{Media Affordances for Environmental Shaping}

The results show that the use of websites and blogs increased the degree of success when the purpose was network building. Websites and blogs commonly offer a greater affordance of connecting ties and a lower affordance of visualizing network information. Users connect ties with the asymmetric connection mode (users do not need to obtain the confirmation from their counterparts to establish relations) and instrumental tie type (users are connected with information flows). Furthermore, users do not have easy access to others' network information in websites and blogs. As shown in an earlier empirical study, these media affordances enable a network to grow at a rapid pace, making it possible to enroll a large number of people (e.g., more than tens of thousands of members) [25].

One notable finding of the present study was that microblogs (e.g., Twitter) had no significant influence on the success of digital activism when the aim was network building. This result contradicts that of a previous digital activism study which reported that social media users commonly used Twitter to access and spread information quickly [49]. We attribute the result to the high affordance of visualizing network information. Twitter may support environmental shaping due to its high number of asymmetric and instrumental ties that facilitate the addition of new ties and the expansion of the network. However, the high visibility of the network information may inhibit social homogenization toward network building. Ultimately, visualizing network information that allows for third parties to easily identify the network information can limit the willingness of people to join the network, thereby adversely affecting the construction of sustainable digital activism. Based on these results, we conjecture that Twitter may be effective for spreading messages to multiple recipients and for accessing a large quantity of information from diverse sources [42]. However, it is not effective for either building a sustainable network where people with common interests communicate or mobilizing others to practice collective action.

The results also showed that media with low affordance of connecting ties and high visualizing network information (e.g., social networks) decreased the degree of success when the aim of digital activism was network building. We assert that particular features may make individuals hesitant to participate in network-building activities. Examples of these include media ties based on emotional ties (such as friendship and strong ties), in which intensive time and effort must be invested to establish and maintain the relationships [20,39].

\subsection{Synthesis and Media Affordances for Contagion}

The results demonstrated that the use of social networks (e.g., Facebook), video sharing, and digital maps increased the degree of success when the purpose of digital activism was synthesis. The results indicate that media with greater affordances for contagion (deep profiling and controlling privacy) lead to improved synthesis. As previously discussed, some affordances (e.g., deep profiling and controlling privacy) help induce homogeneity among collectives and lead to the development of contagion. By increasing the familiarity of the communication context, deep profiling and controlling privacy create the dynamic potential for collectives to shape opinions, aggregate diverse perspectives, and coordinate, create, and share information. For example, users of social networks (e.g., Facebook) can interact within their network of 
friends by making other users their "friends." Individuals can better identify people that share similar interests in a particular cause by obtaining social cues from their profile information, which would be impossible in an anonymous digital environment. These affordances assist people in building a shared mental model. In addition, in an environment that facilitates deep profiling and controlling privacy, individuals may better understand the context in which they exchange sensitive information, and they may feel more comfortable developing a mutual understanding on the basis of personal information, thus helping collectives to achieve the synthesis purpose of digital activism [10, 24].

Our work also revealed that any mismatch between the purposes of digital activism and media affordances negatively influenced the success of digital activism. Specifically, the results showed that the use of blogs negatively influenced the success of digital activism when the aim of digital activism was synthesis. As discussed above, ties in blogs are usually forged by anonymous users, and the digital content of blogs is not strictly controlled. These affordances (low deep profiling and low controlling privacy) may inhibit social homogeneity involving a collective's political deliberation, thus preventing it from reaching an agreement or a consensus when it comes to important decision-making.

Employing the lens of media affordances, we found that social media provide different affordances that appeared to enable or constrain collective action. Our work demonstrates the need to examine the roles of media affordances in promoting particular collective action from a homogeneity perspective to predict the collective performance. The study extends prior research on media choice by shifting the focus from the specific technological features to media affordances. The affordance approach moves scholarly attention away from specific media platforms to the configuration of these platforms, as examined here through latent class logit regression.

\subsection{Implications}

This study examined the appropriateness of different digital media for specific digital activism purposes. In doing so, it contributes to extending our understanding of the effects of technologies on collective action from a novel perspective. First, we extended affordance theory to collective action by utilizing the specific context of digital activism. Scholars have suggested that social media affordances are significantly different from those in conventional digital media, such as email, instant messaging, video conferencing, and group decision support systems [33, 37]. This suggests that research that empirically examines how these unique affordances of social media impact the behavior of individuals as they seek to accomplish particular types of collective action is timely. Therefore, this work provides a first step in that direction. Exploring new affordances of social media and examining how they influence individuals' behaviors in achieving particular collective purposes offers the advantage of determining the best form of media usage for digital activism.

Second, this study contributes to understanding the dynamics of collectives in a digital environment. Despite increasing scholarly attention on how social media serve as platforms to bring together and homogenize large numbers of geographically dispersed individuals to focus on particular activities, little is known about the impact of technology on the homogenization of individuals via a media platform. This work provides a vehicle for researchers to explore the technical designs that must be considered in order to ensure a better understanding of the dynamics of collectives. In so doing, this research extends beyond the theoretical lens of media affordances that are limited to the individual behaviors of small-group dynamics in a digital environment. Digital activism is an important phenomenon today; thus, we call on researchers to examine it in terms of its effectiveness, individual antecedents, organizational antecedents, and the various contexts in which it is either more or less effective.

At the methodological level, the use of latent class regression provides a novel approach to the study of digital activism. Digital activism research has traditionally relied on rich data collected from multiple sources. Instead of relying on traditional empirical approaches, the current study does not hypothesize $e x$ ante media configurations; rather, it relies on latent class analysis to identify the efficacious configurations necessary to increase the degree of success in digital activism. The complex multilevel, multicontextual, and multifaceted dynamics of digital activism activities limit the use of a priori specifications required for regressions or structural equation models. We relied on a more flexible estimation approach, which is a hybrid between traditional empirical models based on regression, and the need for flexibility in model specification when nomological validity in the emerging area of digital activism is limited. The latent class approach allowed us to identify the configurations of the purposes of digital activism 
(network building and synthesis) and the media tools (ranging from blogs to E-petitions) that increased or decreased the degree of success.

\subsection{Limitations}

The findings of this study must be interpreted in light of its limitations. First, the outcomes of digital activism depend on complex social, economic, political, and cultural factors. Media tools play an important role in the sharing and transmission of information. However, the current results should not be construed to indicate that media tools 'make or break' digital activism efforts. Instead, the 'fit' between media tools and the purposes of digital activism are correlated with the activism success.

Second, this model's limitation derives from the difficulty of completely separating the two types of activism: network building and synthesis. It can be difficult to isolate the purposes of activism because it often consists of a mixture of the two types of purposes. Here, we assume the predominance of one goal over the other. It must be acknowledged that the nature of the proposed model is not deterministic. The influence of one purpose does not imply the absence of the other.

\section{References}

[1] R.L. Andrews and I.S. Currim, "Retention of Latent Segments in Regression-based Marketing Models", International Journal of Research in Marketing, 2003, 20(4): p. 315-321.

[2] M. Aouragh and A. Alexander, "The Egyptian Experience: Sense and Nonsense of the Internet Revolution", International Journal of Communication, 2011, 5: p. 13441358 .

[3] W. Bennett, "Communicating Global Activism", Information, Communication \& Society, 2003, 6(2): p. 143168.

[4] B. Bimber, A.J. Flanagin, and C. Stohl, "Reconceptualizing Collective Action in the Contemporary Media Environment", Communication Theory, 2005, 15(4): p. 365-388.

[5] E. Brynjolfsson and A. Saunders, Wired for Innovation: How Information Technology is Reshaping the Economy. Cambridge: MA: MIT Press Books,2009.

[6] M. Buchanan and S. El Batrawy, "Social Media during the Egyptian Revolution: Egyptian Nationals at Home and Abroad", Media, Communication and Cultural Studies Association, 2013, 6(3): p. 75-89.

[7] R.S. Burt, Structural Holes: The Social Structure of Competition. Cambridge: Harvard University Press, 1992.

[8] M. Castells, Communication Power. Oxford: Oxford University Press, 2009.
[9] A. Choudhary, W. Hendrix, K. Lee, D. Palsetia, and W.K. Liao, "Social Media Evolution of the Egyptian Revolution", Communications of the ACM, 2012, 55(5): p. 74-80.

[10] M. Conroy, J.T. Feezell, and M. Guerrero, "Facebook and Political Engagement: A Study of Online Political Group Membership and Offline Political Engagement", Computers in Human Behavior, 2012, 28(5): p. 1535-1546.

[11] T.M. Coopman, "Networks of Dissent: Emergent Forms in Media Based Collective Action", Critical Studies in Media Communication, 2011, 28(2): p. 153-172.

[12] L.M. de Menezes, S. Wood, and G. Gelade, "The Integration of Human Resource and Operation Management Practices and its Link with Performance: A Longitudinal Latent Class Study", Journal of Operations Management, 2010, 28(6): p. 455-471.

[13] A.R. Dennis, R.M. Fuller, and J.S. Valacich, "Media, Tasks, and Communication Processes: A Theory of Media Synchronicity", MIS Quarterly, 2008, 32(3): p. 575-600.

[14] B. Dervin, "On Studying Information Seeking and Use Methodologically: The Implications of Connecting Metatheory to Method", Information Processing \& Management, 1999, 35(6): p. 727-750.

[15] W.S. DeSarbo, C.A. Di Benedetto, K. Jedidi, and M. Song, "Identifying Sources of Heterogeneity for Empirically Deriving Strategic Types: A Constrained Finite-mixture Structural-equation Methodology", Management Science, 2006, 52(6): p. 909-924.

[16] W.S. DeSarbo, R. Grewal, and J. Wind, "Who Competes with Whom? A Demand-based Perspective for Identifying and Representing Asymmetric Competition", Strategic Management Journal, 2006, 27(2): p. 101-129.

[17] A.A. Dini, F. Wahid, and Ø. Sæbø. Affordances and Constraints of Social Media Use in eParticipation: Perspectives from Indonesian Politicians. in PACIS. 2016.

[18] P.C. Fiss, "A Set-theoretic Approach to Organizational Configurations", Academy of Management Review, 2007, 32(4): p. 1180-1198.

[19] K. Foot and S.M. Schneider, Web Campaigning. Cambridge: MIT Press, 2006.

[20] D.E. Gibbons, "Friendship and Advice Networks in the Context of Changing Professional Values", Administrative Science Quarterly, 2004, 49(2): p. 238-262.

[21] J.J. Gibson, The Ecological Approach to Visual Perception. Boston: Houghton Mifflin,1979.

[22] W.J. Grant, B. Moon, and J. Busby Grant, "Digital Dialogue? Australian Politicians' Use of the Social Network Tool Twitter", Australian Journal of Political Science, 2010, 45(4): p. 579-604.

[23] R. Gross and A. Acquisti. Information Revelation and Privacy in Online Social Networks. in Proceedings of the 2005 ACM Workshop on Privacy in the Electronic Society. 2005. ACM.

[24] D. Halpern and J. Gibbs, "Social Media as a Catalyst for Online Deliberation? Exploring the Affordances of Facebook and YouTube for Political Expression", Computers in Human Behavior, 2013, 29(3): p. 1159-1168. 
[25] R.K.F. Ip and C. Wagner, "Weblogging: A study of Social Computing and Its Impact on Organizations", Decision Support Systems, 2008, 45(2): p. 242-250.

[26] M. Joyce, A. Rosas, and P.N. Howard, Global Digital Activism Data Set, ICPSR34625-v1. 2013, Inter-university Consortium for Political and Social Research: Ann Arbor, MI.

[27] M.C. Joyce, Digital Activism Decoded: the New Mechanics of Change. IDEA, New York,2010.

[28] J.S. Juris, "The New Digital Media and Activist Networking within Anti-Corporate Globalization Movement", The ANNALS of the American Academy of Political and Social Science, 2005, 597(1): p. 189-208.

[29] G.C. Kane, M. Alavi, G.J. Labianca, and S. Borgatti, "What's Different about Social Media Networks? A Framework and Research Agenda", MIS Quarterly, 2012, 38(1): p. 275-304.

[30] A. Kende, M. van Zomeren, A. Ujhelyi, and N.A. Lantos, "The Social Affirmation Use of Social Media as a Motivator of Collective Action", Journal of Applied Social Psychology, 2016, 46: p. 453-469.

[31] G. Langlois, G. Elmer, F. McKelvey, and Z. Devereaux, "Networked Publics: The Double Articulation of Code and Politics on Facebook", Canadian Journal of Communication, 2009, 34(3): p. 415-434.

[32] F.L. Lee, H.-T. Chen, and M. Chan, "Social Media Use and University Students' Participation in a Large-scale Protest Campaign: The Case of Hong Kong's Umbrella Movement", Telematics and Informatics, 2017, 34(2): p. 457469.

[33] P.M. Leonardi, "When Flexible Routines Meet Flexible Technologies: Affordance, Constraint, and the Imbrication of Human and Material Agencies", MIS quarterly, 2011, 35(1): p. $147-167$.

[34] G. Lotan, E. Graeff, M. Ananny, D. Gaffney, and I. Pearce, "The Revolutions were Tweeted: Information Flow during the 2011 Tunisian and Egyptian Revolutions", International Journal of Communication, 2011, 5: p. 13751405.

[35] V.V. Lysenko and K.C. Desouza, "Moldova's Internet Revolution: Analyzing the Role of Technologies in Various Phases of the Confrontation", Technological Forecasting and Social Change, 2012, 79(2): p. 341-361.

[36] M. Ma and R. Agarwal, "Through a Glass Darkly: Information Technology Design, Identity Verification, and Knowledge Contribution in Online Communities", Information Systems Research, 2007, 18(1): p. 42-67.

[37] A. Majchrzak, S. Faraj, G.C. Kane, and B. Azad, "The Contradictory Influence of Social Media Affordances on Online Communal Knowledge Sharing", Journal of Computer-Mediated Communication, 2013, 19(1): p. 38-55.

[38] J.E. McGrath, Groups: Interaction and Performance. Prentice Hall 1984.

[39] A. Mehra, M. Kilduff, and D.J. Brass, "The Social Networks of High and Low Self-monitors: Implications for Workplace Performance", Administrative Science Quarterly, 2001, 46(1): p. 121-146.
[40] B.S. Noveck, Wiki Government: How Technology can Make Government Better, Democracy Stronger, and Citizens more Powerful. Washington, DC: Brookings Institution Press, 2009.

[41] W. Oh and S. Jeon, "Membership Herding and Network Stability in the Open Source Community: The Ising Perspective", Management Science, 2007, 53(7): p. 10861101.

[42] J. Penney and C. Dadas, "(Re)Tweeting in the Service of Protest: Digital Composition and Circulation in the Occupy Wall Street Movement", New Media \& Society, 2013, 16(1): p. 74-90.

[43] T. Postmes and S. Brunsting, "Collective Action in the Age of the Internet: Mass Communication and Online Mobilization", Social Science Computer Review, 2002, 20(3): p. 290-301

[44] R.D. Putnam, Democracies influx: The Evolution of Social Capital in Contemporary Society. New York: Oxford University Press, 2002.

[45] R.D. Putnam, L. Feldstein, and D.J. Cohen, Better Together: Restoring the American Community. New York: Simon \& Schuster,2003.

[46] L. Qiu, Q. Tang, and A.B. Whinston, "Two Formulas for Success in Social Media: Learning and Network Effects", Journal of Management Information Systems, 2015, 32(4): p. 78-108.

[47] S. Rosenstone and J.M. Hansen, Mobilization, Participation, and Democracy in America. New York: Longman,2003.

[48] S. Rosenstone and J.M. Hansen, Mobilization, Participation, and Democracy in America. New York: Macmillan,1993.

[49] A. Segerberg and W.L. Bennett, "Social Media and the Organization of Collective Action: Using Twitter to Explore the Ecologies of two Climate Change Protests", The Communication Review, 2011, 14(3): p. 197-215.

[50] E. Stepanova, "The Role of Information Communication Technologies in the "Arab Spring" : Implications beyond the Region", PONARS Eurasia, 2011, 159: p. 1-6.

[51] H. Sun, "A Longitudinal Study of Herd Behavior in the Adoption and Continued Use of Technology", MIS Quarterly, 2013, 37(4): p. 1013-1041.

[52] J. Sutanto, E. Palme, C.-H. Tan, and C.W. Phang, "Addressing the Personalization-Privacy Paradox: An Empirical Assessment from a Field Experiment on Smartphone Users", MIS Quarterly, 2013, 37(4): p. 11411164.

[53] E.E. Umphress, G. Labianca, D.J. Brass, E. Kass, and L. Scholten, "The Role of Instrumental and Expressive Social Ties in Employees' Perceptions of Organizational Justice", Organization Science, 2003, 14(6): p. 738-753.

[54] M. Wedel and W.A. Kamakura, Market Segmentation: Conceptual and Methodological Foundations. Boston, MA: Kluwer,2000.

[55] G. Wolf, "Weapons of Mass Mobilization", Wired, 2004, 12(9): p. 131-137. 